\title{
Design and performance evaluation of 1-by-64 multimode interference power splitter for optical communications
}

\author{
Rasmussen, Thomas; Rasmussen, Jesper Kiel; Povlsen, Jørn Hedegaard
}

Published in:

Journal of Lightwave Technology

Link to article, DOI:

$10.1109 / 50.469726$

Publication date:

1995

Document Version

Publisher's PDF, also known as Version of record

Link back to DTU Orbit

Citation (APA):

Rasmussen, T., Rasmussen, J. K., \& Povlsen, J. H. (1995). Design and performance evaluation of 1-by-64 multimode interference power splitter for optical communications. Journal of Lightwave Technology, 13(10), 2069-2074. https://doi.org/10.1109/50.469726

\section{General rights}

Copyright and moral rights for the publications made accessible in the public portal are retained by the authors and/or other copyright owners and it is a condition of accessing publications that users recognise and abide by the legal requirements associated with these rights.

- Users may download and print one copy of any publication from the public portal for the purpose of private study or research.

- You may not further distribute the material or use it for any profit-making activity or commercial gain

- You may freely distribute the URL identifying the publication in the public portal 


\title{
Design and Performance Evaluation of 1-by-64 Multimode Interference Power Splitter for Optical Communications
}

\author{
Thomas Rasmussen, Jesper Kiel Rasmussen, and Jørn Hedegaard Povlsen
}

\begin{abstract}
A 1-by-64 multimode interference power splitter in $\mathrm{SiO}_{2}$ has been designed for use in fiber-optics communication systems. The splitter exhibits a minimum loss of $0.5 \mathrm{~dB}$ and a uniformity of $1.7 \mathrm{~dB}$ at a wavelength of $1.55 \mu \mathrm{m}$. The polarization sensitivity is below $0.14 \mathrm{~dB}$, the reflection level below $-55 \mathrm{~dB}$, and the optical bandwidth $30 \mathrm{~nm}$. The fabrication tolerances are \pm 0.1 mm on the length and $\pm 3.5 \mu \mathrm{m}$ on the width of the multimode section of the splitter. In comparison with a branching-type splitter it is found that the designed device is approximately $\mathbf{3 0 \%}$ shorter than the branching-type device for comparable losses.
\end{abstract}

\section{INTRODUCTION}

$\mathbf{I}_{\mathrm{p}}^{\mathrm{O}}$ N OPTICAL communication networks for distribution purposes (for instance Cable-TV) there is a need for 1-by$N$ optical power splitters. Typical numbers of splittings $N$ would be from 16 to 256 or more. Some of the important performance characteristics of such splitters are; low losses and reflections, compatibility with optical single-mode fibers, uniform distribution of the output power on the $N$ waveguides and a low price.

For low numbers of splittings $(N<16)$ the splitter could be made as a fused bundle of optical fibers [1] but, for larger numbers of splittings integrated optical solutions [2]-[4] become attractive. The most obviuos way of designing an optical waveguide power splitter would be to make it as a cascade of 1-by-two waveguide branches [2]. However, the processing of the branching point, where the two waveguides start to separate, is technologically very difficult [5]. This generally leads to problems with the uniformity over all the output waveguides of the power and with uniformity among different samples. Recently, the self- and multiimaging effect [6] in optical multimode waveguides have been used to perform 1-by- $N$ optical power splitting [9], [10]. Such devices are denoted multimode interference (MMI) power splitters. In this design the sharp edges near the branching points are avoided thus leading to a more procestolerant design. Furthermore, the MMI power splitters are potentially shorter than their branching-type counterparts [11].

Most of the MMI-devices presented so far have been made in relatively strong guidance waveguide structures, such as arises in many III-V semiconductor technologies. In this paper we will however concentrate on weakly guiding glass

Manuscript received December 8, 1994; revised June 7, 1995. This work was supported by the National Agency of Industry and Trade and the Danish Technical Research Council.

The authors are with the Electromagnetics Institute, Technical University of Denmark, DK-2800 Lyngby, Denmark.

IEEE Log Number 9414414. waveguides with step refractive index profile. This structure is inherent in the silica-on-silicon technology used to produce fiber-compatible integrated optical devices [12]. We will design a 1-by-64 MMI power splitter and characterize it with respect to polarization sensitivity, reflection level, wavelength response and proces tolerances. Thereby, we will expose the predicted performance of MMI power splitters and discuss this performance in relation to typical demmands in optical fiber communications.

\section{DESIGN}

In this section we will describe the design of a 1-by-64 multimode interference power splitter. In Fig. 1 the geometry of the splitter is shown. Fig. 1 also defines the characteristic parameters for the power splitter. $a$ is the core width of the single-mode waveguides, $n_{1}$ and $n_{2}$ the refractive index of the core and cladding, respectively, $W$ and $L_{M M I}$ the width and length of the multimode waveguide section, respectively, $L_{0}^{\mathrm{MMI}}$ the length of the output $S$-bends, and $D$ is the centerto-center distance between the waveguides at the output. The distance between neighboring output waveguides at the end of the multimode section is $W / 64$ as described in [6].

The power splitter will be designed for the third telecommunication window, i.e., a wavelength, $\lambda$, of $1.55 \mu \mathrm{m}$. For compatibility with optical single-mode fibers the core width $a$ is chosen to $6 \mu \mathrm{m}$, the effective refractive index difference to 0.005 , and the base material (the cladding) to $\mathrm{SiO}_{2}$. At a wavelength of $1.55 \mu \mathrm{m}$ the cladding refractive index is thus 1.445. $D$ is chosen to $250 \mu \mathrm{m}$ to allow for fiber connections taken into account the typical cladding thickness of optical fibers of $125 \mu \mathrm{m}$.

The analysis of Ulrich and Ankele [7] showed that the length of the multimode section may be calculated approximately by

$$
L_{\mathrm{MMI}}=\frac{n_{1} W^{2}}{N \lambda}
$$

where, in our case, the number of splittings, $N$, equals 64 . This equation is found under the assumption that the propagation constant of the optical modes depends quadratically on the mode number. This is a very good approximation as illustrated on Fig. 2.

We used the finite difference beam propagation method (FDBPM) [14] to calculate the field evolution through the structure. As described in [14] we use a nonequidistant mesh for the discretisation that is fine near the waveguide cores and gradually gets harsher when moving away from the cores. 


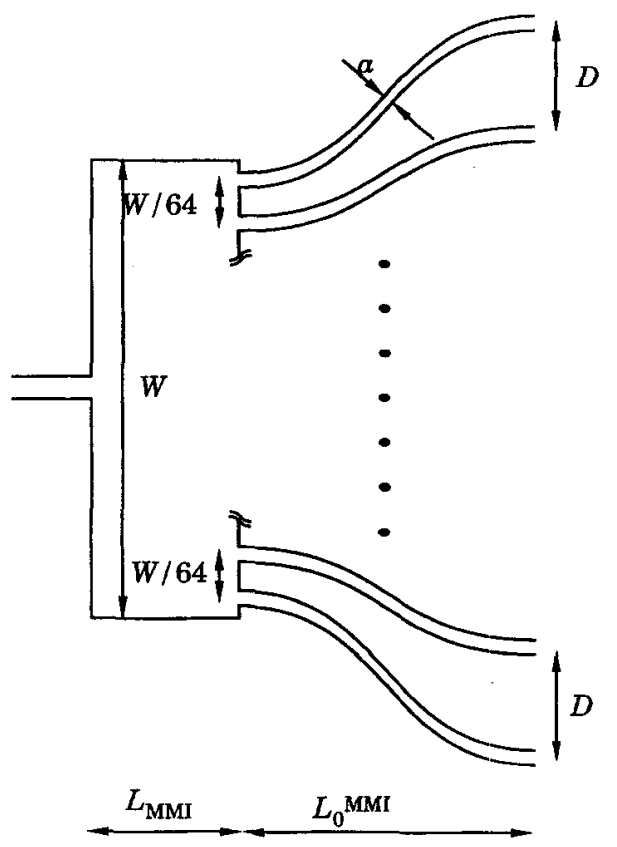

Fig. 1. Geometry of 1-by-64 MMI power splitter. The cladding refractive index is $n_{2}$ and the core refractive index is $n_{1}$.

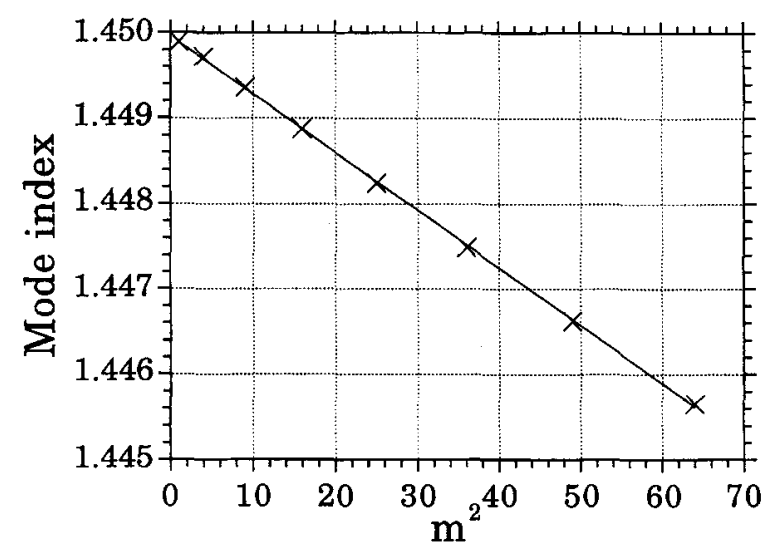

Fig. 2. Mode index for the guided modes of a slab waveguide of width 50 $\mu \mathrm{m}$ at a wavelength of $1.55 \mu \mathrm{m}$ as a function of the mode number squared. The core and cladding refractive index is 1.450 and 1.445 , respectively. The crosses indicate the actual mode indices while the solid line is a linear fit.

Thus, the array sizes and computer time needed are limited even for the larger multimode interference splitters. The reason for using the FDBPM is that all the guided and nonguided modes are automatically included in the calculations. Therefore, the coupling between the modes propagating in the output waveguide array is calculated accurately by the FDBPM. We checked the accuracy of the FDBPM by comparing results obtained by this method with results obtained by a propagating mode method, where only the guided modes of the multimode section were included. The results were almost identical.

In Fig. 3 we have shown the uniformity, defined as the maximum output power divided by the minimum output power, and the total excess loss; both as functions of the width, $W$, with the length, $L_{\mathrm{MMI}}$ adjusted to give the best (lowest) loss. As seen from Fig. 3 the loss is almost independent on the width $W$ while the uniformity exhibits a more complex dependence

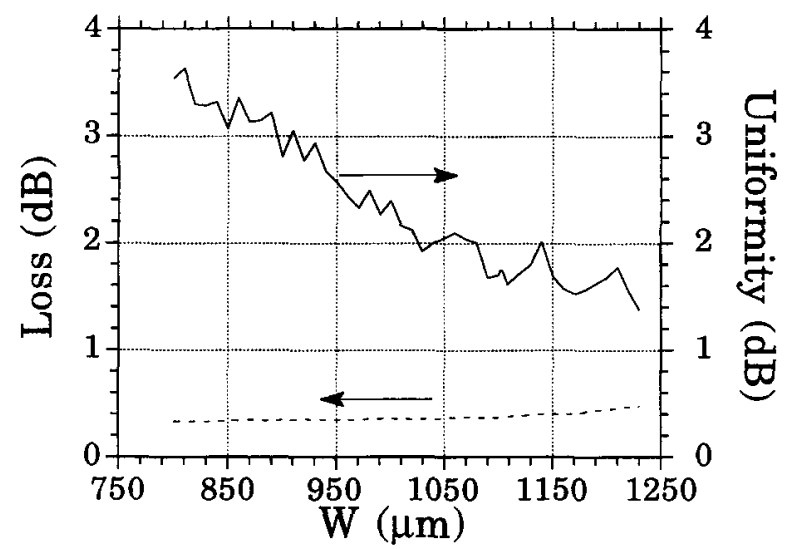

Fig. 3. Uniformity and excess loss of the multimode section of a 1-by-64 MMI power splitter as a function of the waveguide width $W$. The length $L_{\mathrm{MMI}}$ has been adjusted for every value of $W$ to obtain minimum loss.

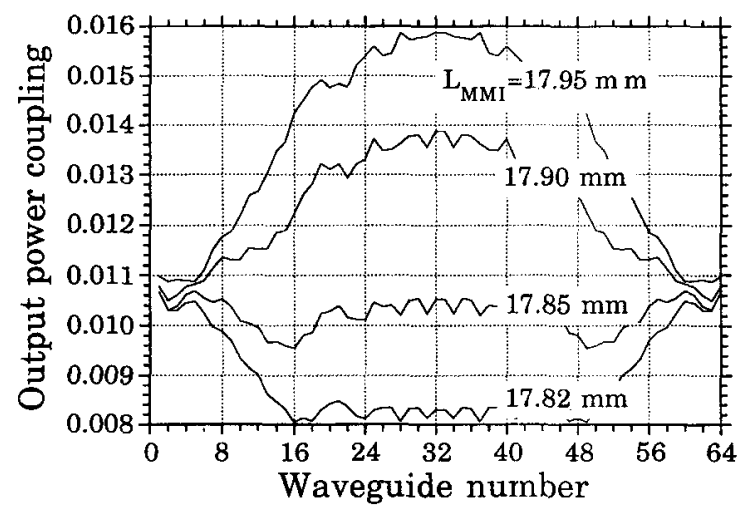

Fig. 4. Distribution of output power on the 64 output waveguide as a function of the waveguide number width the length of the multimode section as parameter. The waveguides 1 and 64 are the outermost waveguides. The width of the multimode section is $1.105 \mathrm{~mm}$.

on $W$. The overall behavior although, is a decreasing function of $W$.

We have chosen $W=1.105 \mathrm{~mm}$ for the 1-by-64 power splitter. The corresponding length of the multimode section is $L_{\mathrm{MMI}}=17.953 \mathrm{~mm}$. For this design the loss at a wavelength of $1.55 \mu \mathrm{m}$ is $0.4 \mathrm{~dB}$ and the uniformity is $1.7 \mathrm{~dB}$. Using 1 we get $L_{\mathrm{MMI}}=17.848 \mathrm{~mm}$, thus 1 and the BPM-simulations are in close agreement. In Fig. 4 we have shown the distribution of output power on the 64 output waveguides for $W=1.105$ $\mathrm{mm}$ and four different values of $L_{\mathrm{MMI}}$ at and just below 17.95 $\mathrm{mm}$. As seen, the uniformity is best $(0.5 \mathrm{~dB})$ at a length of around $17.85 \mathrm{~mm}$. However, the loss at this length is $1.8 \mathrm{~dB}$. Furthermore, as will become evident from the analysis of the bandwidth and tolerances in the following sections, our choice of the design with the lowest loss leads to a less critical device performance than the design where the lowest uniformity is chosen.

The length of the $S$-bends in the output array where the waveguides is branched from a separation of $W / 64=17.3$ $\mu \mathrm{m}$ to $250 \mu \mathrm{m}$ is found by requiring a maximum bending loss of $0.1 \mathrm{~dB}$ in each bend. As shown in [13] cosine-shaped $S$ bends is characterized by the normalized parameter $F_{s}(B, \alpha)$, where $B=2 a \sqrt{n_{1}^{2}-n_{2}^{2}} / \lambda$ is the normalized frequency, and 


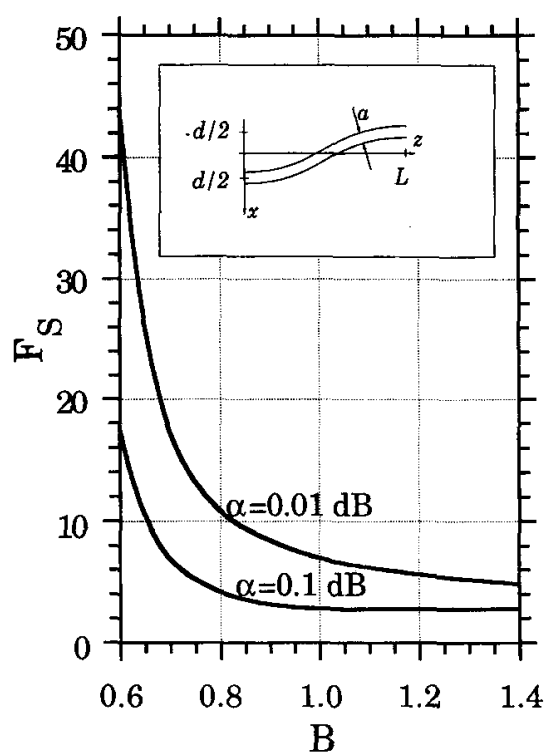

Fig. 5. The characteristic parameter of an $S$-bend $F_{s}$ as a function of the normalized frequency $B$ with the acceptable loss of the bend as parameter. The $S$-bend is defined on the inset.

TABLE I

Data for the Designed 1-BY-64 MMI Power SplitTer

\begin{tabular}{|l|r|}
\hline \multicolumn{2}{|c|}{ Design } \\
\hline$D$ & $250 \mu \mathrm{m}$ \\
$L_{M M I}$ & $17.95 \mathrm{~mm}$ \\
$W$ & $1.105 \mathrm{~mm}$ \\
$a$ & $6.0 \mu \mathrm{m}$ \\
$\Delta n$ & 0.005 \\
$L_{0}^{M M I}$ & $23.92 \mathrm{~mm}$ \\
Total dimensions & $41.87 \times 15.76 \mathrm{~mm}^{2}$ \\
\hline
\end{tabular}

$\alpha$ is the loss. In Fig. $5 F_{s}$ is shown as a function of $B$ with the acceptable loss of the $S$-bend as parameter.

The length of the $S$-bend is connected to $F_{s}$, the offset $d$, and the other waveguide parameters by [13]

$$
L=\pi \sqrt{\frac{F_{s} d \lambda\left(n_{2}\right)^{1 / 2}}{2(\Delta n)^{3 / 2}}} .
$$

In the present case the largest loss must be expected for the outermost waveguides for which $d=7.33 \mathrm{~mm}$. The normalized frequency is calculated to 0.93 . From Fig. 5 we read $F_{s}=3.0$ at this value of $B$ and from 2 we finally get $L_{0}^{M M I}=23.92 \mathrm{~mm}$. The total length of the splitter thus becomes $41.87 \mathrm{~mm}$ while the total width is $15.76 \mathrm{~mm}$. In Table I we have summarized the design of the 1-by-64 MMI power splitter.

\section{PERFORMANCE}

\section{A. Polarization Dependence}

As the waveguide structure we are considering is weakly guiding it must be expected that the structure is almost polarization independent. We calculated the birefringence induced by the waveguide geometry to be below $1 \times 10^{-5}$ between the two othogonal polarizations (TE and TM). However, the different expansion coefficient of silica and silicon leads to a stress induced birefrigence of typically $4 \times 10^{-4}$ [15]. The calculations presented in the previous section were for the transverse electrical (TE) polarized modes $\left(\Delta n_{\mathrm{eff}, \mathrm{TE}}=0.0050\right)$. The corresponding effective refractive index difference for the transverse magnetic (TM) modes is $\Delta n_{\mathrm{eff}, \mathrm{TM}}=0.0046$. We did also calculate the excess loss and the uniformity for the TM fundamental mode as input. The result was $1.848 \mathrm{~dB}$ for the uniformity and $0.408 \mathrm{~dB}$ for the loss. This should be compared with a uniformity of $1.712 \mathrm{~dB}$ and a loss of $0.373 \mathrm{~dB}$ for the TE-polarization. The polarization dependence of this device is thus $0.035 \mathrm{~dB}$ for the loss and $0.136 \mathrm{~dB}$ for the uniformity.

\section{B. Reflections}

Due to the abrupt change in waveguide width from the input single-mode waveguide to the multimode waveguide a reflected field must be expected. This reflection will however be small due to the small difference between the core and cladding refractive index (0.005). For plane waves in $\mathrm{SiO}_{2}$ with perpendicular incidence on a refractive index step of 0.005 the power reflection is $-55 \mathrm{~dB}$. We calculated the reflected field at the input of the device by the 2-dimensional Fourier-expansion method [16] and found that the reflection was below $-40 \mathrm{~dB}$, which was the accuracy of our method. Thus, the reflection from a MMI-power splitter must be expected to be $-55 \mathrm{~dB}$ or less.

\section{Wavelength Response}

In Fig. 6 we have shown the uniformity and loss of the designed 1-by-64 power splitter (see Table I) as a function of the wavelength. If a uniformity of $2 \mathrm{~dB}$ is accepted we see that the optical bandwidth is around $30 \mathrm{~nm}$. This narrow bandwidth is due to the fact that the multiple-imaging process is very phase sensitive. As seen, the uniformity may be lower than the $1.7 \mathrm{~dB}$ at the center wavelength of $1.55 \mu \mathrm{m}$, by using 1.538 or $1.560 \mu \mathrm{m}$ as center wavelength. However, this will lead to an asymmetric wavelength response with a very critical lower or upper tolerance on the wavelength. From the approximate formula 1 we see that $L_{\mathrm{MMI}}$ and $\lambda$ are equivalent. Therefore, this problem is identical to the one that was discussed in Section II in connection with Fig. 4 about whether the choice of $L_{\mathrm{MMI}}$ should be the one leading to the lowest loss or the lowest uniformity.

\section{Tolerances}

To evaluate the fabrication tolerances on the MMI-power splitter we have calculated the loss and uniformity for fixed $W$ and varying $L_{\mathrm{MMI}}$ and vice versa. The results are shown on Figs. 7 and 8 . As seen, the most critical parameter is the loss. If an extra loss of $1.0 \mathrm{~dB}$ is accepted we see that this correponds to a change in the length of the multimode section of $\pm 0.1 \mathrm{~mm}$ for fixed width, $W=1.105 \mathrm{~mm}$. Correspondingly, the width should be controlled within $\pm 3.5 \mu \mathrm{m}$ to keep the excess loss below $1.0 \mathrm{~dB}$ when $L_{\mathrm{MMI}}$ is fixed at $17.593 \mathrm{~mm}$. Thus, the width is the most critical parameter, as was also found for other waveguide geometries [5]. As have alredy been mentioned, 


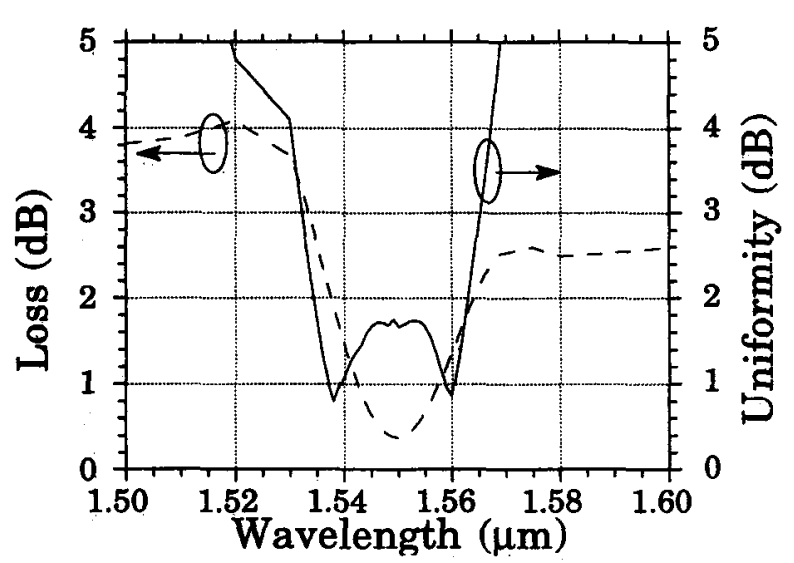

Fig. 6. Wavelength response of the designed 1-by-64 MMI power splitter.

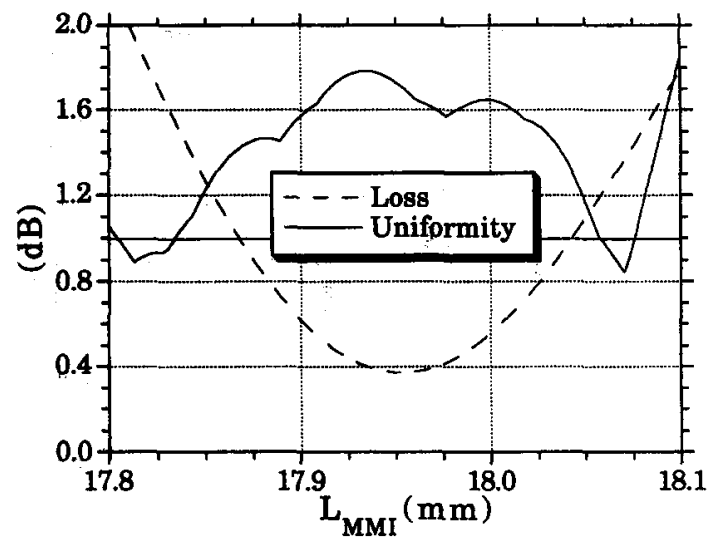

Fig. 7. Loss and uniformity versus the length of the multimode section of the 1-by-64 MMI power splitter with the width fixed at $1.105 \mathrm{~mm}$.

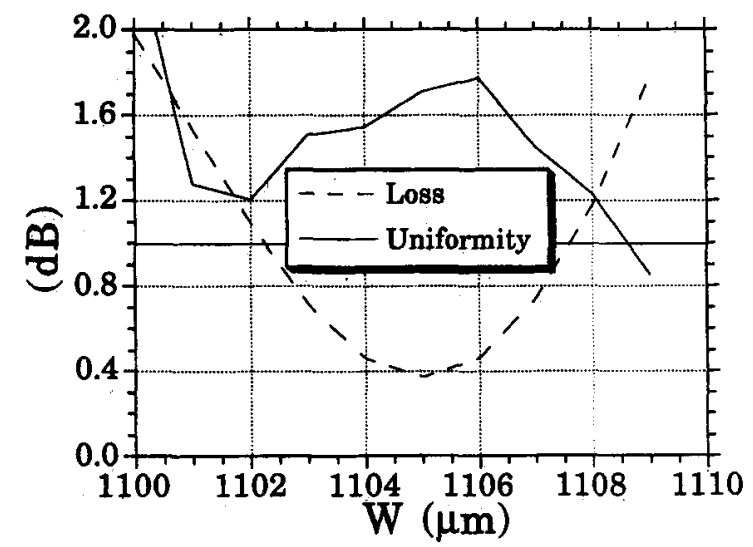

Fig. 8. Loss and uniformity versus the width of the multimode section of the 1-by-64 MMI power splitter with the length fixed at $17.953 \mathrm{~mm}$.

the uniformity at $1.55 \mu \mathrm{m}$ may be improved by using a length $L_{\text {MMI }}$ or width $W$ different from the one leading to the lowest loss. However, Figs. 7 and 8 clearly illustrates that the choice that we have made leads to the most process tolerant device.

\section{DISCUSSION}

In this section we will discuss the performance of the designed MMI-power splitter in the context of optical communications. Furthermore, we shall compare the size and optical bandwidth of this MMI-device with the size and bandwidth of a branching-type power splitter with comparable loss.

\section{A. Performance Evaluation}

The requirements for optical components for optical communication systems are rather strict. Guidelines may be found in [17] and [18]. With respect to the polarization sensitivity, the deviation in uniformity of $0.14 \mathrm{~dB}$ between the two orthogonal polarizations found in Section III-A is generally a minor problem. If neccesary, the birefringence may be reduced by etching stress releasing grooves on each side of the splitter [15].

For digital communication systems the typical requirements on the acceptable reflection level from optical components is in the order of $-30 \mathrm{~dB}$. For analog systems the requirement may be a reflection $25 \mathrm{~dB}$ lower. In both cases the designed MMI-splitter meets the requirements.

In Section III-B we found that the optical bandwidth of the splitter is around $30 \mathrm{~nm}$ centered at a wavelength of 1.55 $\mu \mathrm{m}$. This bandwidth nearly coincides with the amplification bandwidth of Erbium-doped fiber amplifiers which are needed for loss compensation in distribution networks. Therefore, the limited optical bandwidth will not pose a problem in a practical system.

Finally, the tolerances of $\pm 0.1 \mathrm{~mm}$ on the length and \pm 3.5 $\mu \mathrm{m}$ on the width of the multimode section is obtainable using standard photo-lithographical methods.

\section{B. Comparison with Branching-Type Power Splitter}

As mentioned in the introduction the most straightforward design of a multibranch power splitter consist of a cascading of 1-by-2 $Y$-branches. This is scematically shown on Fig. 9 . In [11] we found that the ratio of the length of a multimode interference splitter to the length of a branching-type splitter may be expressed by

$$
\begin{aligned}
\frac{L_{\mathrm{tot}}^{\mathrm{MMI}}}{L_{\mathrm{tot}}^{B \tau}}= & (\sqrt{2}-1) \frac{\sqrt{1-1 / N}}{1-1 / \sqrt{N}} \\
& \times\left\{K \frac{1}{N \sqrt{N-1}}+\sqrt{1-W /(N D)}\right\}
\end{aligned}
$$

for comparable losses, where

$$
K=\frac{2 n_{2} W^{2}}{\pi \lambda} \sqrt{\frac{(\Delta n)^{3 / 2}}{F_{S} \lambda D\left(n_{2}\right)^{1 / 2}}} .
$$

For $N=64$ and $W=1.105 \mathrm{~mm}$ we get $L_{\text {tot }}^{\mathrm{MMI}}=0.7 \times L_{\mathrm{tot}}^{B \tau}$. Thus the MMI-device is $30 \%$ shorter than it branching-type counterpart.

Ideally the uniformity of the branching-type splitter is $0 \mathrm{~dB}$. However, as discussed in the introduction, the fabrication of the sharp branching point is very difficult and the uniformity will in practical components deviate from $0 \mathrm{~dB}$. A typical value for the uniformity is $0.6 \mathrm{~dB}$ for a 1-by-16 power splitter [19].

In contrast to the MMI-type splitter the branching-type splitter is a mono-mode component. Ideally the power is maintained in the fundamental supermode of the structure throughout the device. Therefore, the optical bandwidth of the branching-type splitter must be expected to be much larger than the bandwidth of the MMI-splitter. In Fig. 10 we have shown the loss of a two-branch power splitter as a function of 

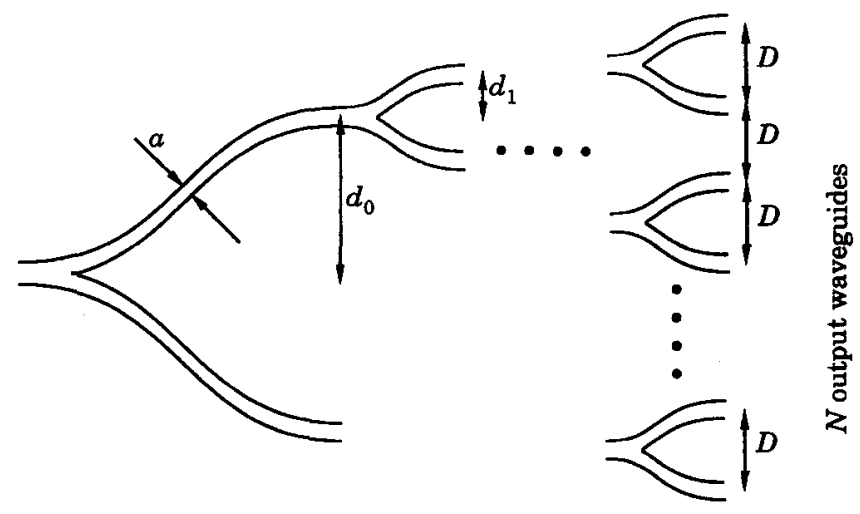

$L_{0}$

$L_{1}$

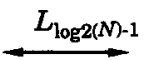

Fig. 9. Geometry of multibranch power splitter.

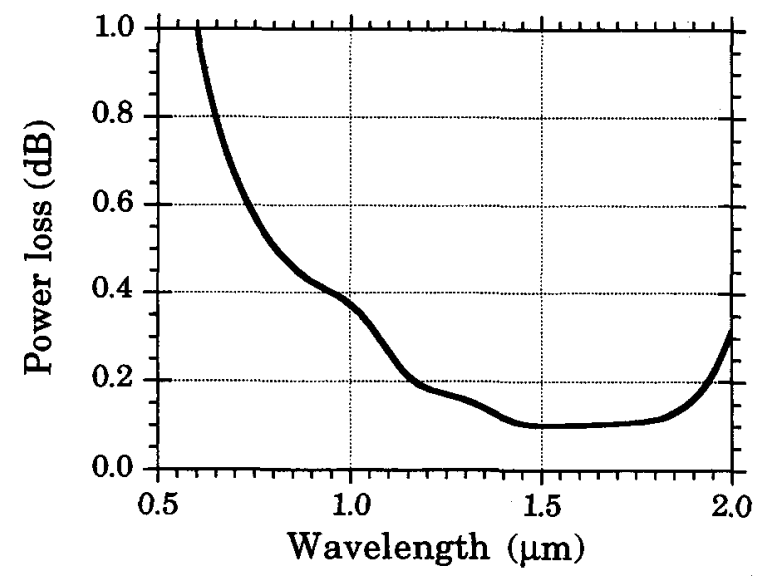

Fig. 10. Wavelength response of symmetric $Y$-branch. The splitter is $2 \mathrm{~mm}$ long with a maximum separation of $50 \mu \mathrm{m}$ between the two waveguides. The cores have square cross sections of $6 \times 6 \mu \mathrm{m}^{2}$ and the refractive index difference is 0.005 .

the wavelength calculated with the beam propagation method [14]. The device parameters are given in the figure caption. As just discussed, the optical bandwidth is seen to be very large. For a 1-by-64 power splitter we need 6 branch sections $(2+4+8+16+32=62 Y$-splitters $)$. If a total loss of $2 \mathrm{~dB}$ is accepted we get an optical bandwidth of $1000 \mathrm{~nm}$ which should be compared to the $30 \mathrm{~nm}$ found for the MMIsplitter. Thus, the same branching-type splitter may be used for both the second $(1.31 \mu \mathrm{m})$ and the third $(1.55 \mu \mathrm{m})$ telecommunication window. This transparancy is off course important for systems where both wavelengths are to be used.

\section{CONCLUSION}

We have designed a 1-by-64 multimode interference (MMI) power splitter for use in fiber-optics communication systems at a wavelength of $1.55 \mu \mathrm{m}$. The total dimensions of the device is a length of $41.87 \mathrm{~mm}$ and a width of $15.76 \mathrm{~mm}$. The insertion loss is calculated to $0.5 \mathrm{~dB}$, while the uniformity, defined as the ratio between the maximum power in an output waveguide and the minimum power in an output waveguide, is $1.7 \mathrm{~dB}$.

With respect to the performance of this device the polarization sensitivity has been found to be below $0.14 \mathrm{~dB}$ and the reflection level below $-55 \mathrm{~dB}$. The optical bandwidth is 30 $\mathrm{nm}$ centered at a wavelength of $1.55 \mu \mathrm{m}$, and the fabrication tolerances, accepting a penalty of $1.0 \mathrm{~dB}$, is $\pm 0.1 \mathrm{~mm}$ on the length and $\pm 3.5 \mu \mathrm{m}$ on the width of the multimode section of the splitter. This performance shows that the MMI-type splitter will meet the requirements for optical communication systems. Especially, the bandwidth of $30 \mathrm{~nm}$ nearly coincides with the amplification bandwidth of erbium-doped fiber amplifiers.

Finally, we have compared the size and the bandwidth of the designed 1-by-64 MMI power splitter with a corresponding multibranch splitter and found that the MMI-type is $30 \%$ shorter than its branching-type counterpart. The bandwidth of the branching-type power splitter is found to be $1000 \mathrm{~nm}$ which should be compared to the $30 \mathrm{~nm}$ bandwidth of the MMI-type splitter. Thus, the former type of splitter may be used simultaneously for the second $(1.31 \mu \mathrm{m})$ and the third $(1.55 \mu \mathrm{m})$ telecommunication window, while the MMI-type must be designed for either of the two windows.

\section{ACKNOWLEDGMENT}

The authors thank E. Nicolaisen for fruitful discussions.

\section{REFERENCES}

[1] J. W. Arkwright, D. B. Mortimore, and R. M. Adnams, "Monolithic $1 \times 19$ singlemode fused fiber couplers," IEE Electron. Lett., vol. 27, no. 9, pp. 737-738, 1991

[2] N. Nourshargh, E. M. Starr, and T. M. Ong, "Integrated optic $1 \times 4$ splitter in $\mathrm{SiO}_{2} / \mathrm{GeO}_{2}$," IEE Electron. Lett., vol. 25, no. 15, pp. 981 , 982, 1989.

[3] S. Day, R. Bellerby, G. Cannell, and M. Grant, "Silicon based fiber pigtailed $1 \times 16$ power splitter," IEE Electron. Lett., vol. 28, no. 10, pp. $920-922,1992$.

[4] Y. Yamada, F. Hanawa, T. Kitoh, N. Takato, and T. Maruno, "Reliability of silica-based planar-lightwave circuit-type $1 \times 8$ splitter module," in Proc. Opt. Fiber Commun. Conf., San José, CA. USA, 1993, paper WH3.

[5] L. Soldano, F. B. Veerman, M. K. Smit, B. H. Verbeek, A. H. Dubost, and E. C. M. Pennings, "Planar monomode optical couplers based on multimode interference effects," J. Lightwave Technol., vol. 10, no. 12, pp. 1843-1850, 1992.

[6] O. Bryngdahl, "Image formation using self-imaging techniques," J. Opt. Soc. $A m$., vol. 63, no. 4, pp. 416-419, 1973.

[7] R. Ulrich and G. Ankele, "Self-imaging in homogeneous planar optical waveguides," Appl. Phys. Lett., vol. 27, no. 6, pp. 337-339, 1975.

[8] R. Ulrich and T. Kamiya, "Resolution of self-images in planar optical waveguides," J. Opt. Soc. Am., vol. 68, no. 5, pp. 583-592, 1978.

[9] R. M. Jenkins, R. W. Devereux, and J. M. Heaton, "Waveguide beam splitters and recombiners based on multimode propagation phenomena," Opt. Lett., vol. 17, No. 14, pp. 991-993, 1992.

[10] J. M. Heaton, R. M. Jenkins, D. R. Wright, J. T. Parker, J. C. H. Birbeck, and K. P. Hilton, "Novel 1-to- $N$ way integrated optical beam splitters using symmetric mode mixing in GaAs/AlGaAs multimode waveguides," Appl. Phys. Lett., vol. 61, no. 15, pp. 1754-1756, 1992.

[11] T. Rasmussen, A. Bjarklev, and J. H. Povlsen, "Length requirement for power splitters in optical communication systems," IEE Electron. Lett., vol. 30, no. 7, pp. 583-584, 1994.

[12] G. Grand, J. P. Jadot, H. Denis, S. Valette, A. Foumier, and A. M. Grouillet, "Low-loss PECVD silica channel waveguides for optical communications," IEE Electron. Lett., vol. 26, no. 25, pp. 2135-2137, 1990.

[13] T. Rasmussen and A. Bjarklev, "General design of fiber compatible integrated optical $S$-bends, power splitters, and directional couplers," in Proc. Opt. Fiber Commun. Conf., San José, CA. USA, 1994, pp. 55-57.

[14] T. Rasmussen, J. H. Povlsen, and A. Bjarklev; "Accurate finite difference beam propagation method for complex integrated optical structures," IEEE Photon. Technol. Lett., vol. 5, no. 3, pp. 339-342, 1993.

[15] N. Takato and A. Sugita, "Silica-based single-mode waveguides and their applications to integrated-optic devices," in Mat. Res. Soc. Symp. Proc, vol. 172, 1990, pp. 253-264.

[16] C. Henry and $Y$. Shani, "Analysis of mode propagation in optical waveguide devices by Fourier expansion," IEEE J. Quantum Electron. vol. 27, no. 4, pp. 523-530, 1991. 
17] Draft CCITT Recommendation G.957, "Optical interfaces for equipments and systems relating to the synchroneous digital hierarchy," CCITT, SGXV, 1990

[18] Bellcore TR 1209, "Generic requirements for fiber optic branching components."

[19] H. Hanafusa, N. Takato, F. Hanawa, T. Oguchi, H. Suda and Y. Ohmori. "Wavelength-insensitive $2 \times 16$ optical splitters developed using planar lightwave circuit technology," IEE Electron. Lett., vol. 28, no. 7, pp. 644-645, 1992

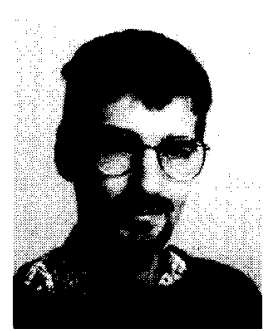

Thomas Rasmussen was born in Copenhagen, Denmark on November 3, 1965. He received the M.Sc. degree in electrical engineering from the Electromagnetics Institute (EMI), Technical University of Denmark (TUD) in 1991. He received the Ph.D. degree from EMI, TUD in 1994. The subject of his Ph.D. thesis was modeling of integrated optical structures for optical communications.

In 1991 he worked as a Research Assistant at EMI on integrated optics and erbium-doped fiber amplifiers. Currently he is working at EMI on integrated optics. He has authored or co-authored more than 50 publications in international journals and at international conferences.

Dr. Rasmussen is a member of the Danish Optical Society and the Optical Society of America.

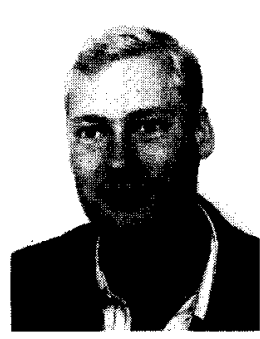

Jesper Kiel Rasmussen was born on March 10, 1979 in Copenhagen. He is presently an M.Sc. student at the Electromagnetics Institute, Technical University of Denmark.

Jorn Hedegaard Povlsen received the M.Sc. degree in physics from the H.C. Ørsted Institute of Copenhagen, Denmark, in 1982.

In 1983 he joined the Electromagnetics Institute, Technical University of Denmark as an Associate Researcher. His interests are in the field of characterization of active and passive optical waveguides and in MQW structures 